Abstract AB1307 - Table 1. Prevalence and direct medical costs of AIRDs in South Korea

\begin{tabular}{|c|c|c|c|c|c|c|c|c|}
\hline \multirow{2}{*}{$\begin{array}{l}\text { Category of } \\
\text { diseases }\end{array}$} & \multicolumn{5}{|c|}{ Number of patients $(\mathrm{N} / 100,000)$} & \multirow{2}{*}{$\begin{array}{c}\text { Change of prevalence between } \\
2012 \text { and } 2016(\%)\end{array}$} & \multirow{2}{*}{$\begin{array}{l}\text { Total direct medical cost } \\
\text { (USD) in } 2016\end{array}$} & \multirow{2}{*}{$\begin{array}{l}\text { Direct medical cost per person } \\
\text { (USD) in } 2016\end{array}$} \\
\hline & 2012 & 2013 & 2014 & 2015 & 2016 & & & \\
\hline Seropositive RA & $\begin{array}{l}70276 \\
(139.6)\end{array}$ & $\begin{array}{l}76441 \\
(151.2)\end{array}$ & $\begin{array}{l}83322 \\
(164.2)\end{array}$ & $\begin{array}{l}90280 \\
(177.2)\end{array}$ & $\begin{array}{l}96330 \\
(188.5)\end{array}$ & 35.0 & $107,255,471.1$ & $1,113.4$ \\
\hline SLE & $\begin{array}{l}15287 \\
(30.4)\end{array}$ & $\begin{array}{c}16304 \\
(32.2)\end{array}$ & $\begin{array}{c}17484 \\
(34.4)\end{array}$ & $\begin{array}{l}18245 \\
(35.8)\end{array}$ & $\begin{array}{l}19441 \\
(38.0)\end{array}$ & 25.3 & $27,694,324.4$ & $1,424.5$ \\
\hline AS & $\begin{array}{c}20132 \\
(40.0)\end{array}$ & $\begin{array}{c}22362 \\
(44.2)\end{array}$ & $\begin{array}{c}24794 \\
(48.8)\end{array}$ & $\begin{array}{l}27311 \\
(53.6)\end{array}$ & $\begin{array}{l}30006 \\
(58.7)\end{array}$ & 46.8 & $78,133,501.3$ & $2,603.9$ \\
\hline Polymyositis & $763(1.5)$ & $810(1.6)$ & $896(1.8)$ & $935(1.8)$ & $1036(2.0)$ & 33.7 & $2,553,296.9$ & $2,464.6$ \\
\hline Dermatomyositis & $935(1.9)$ & $1012(2.0)$ & $1089(2.1)$ & $1159(2.3)$ & $1275(2.5)$ & 34.3 & $3,369,996.6$ & $2,643.1$ \\
\hline Systemic sclerosis & $2648(5.3)$ & $2873(5.7)$ & $3126(6.2)$ & $3271(6.4)$ & $3606(7.1)$ & 34.1 & $5,191,029.1$ & $1,439.6$ \\
\hline Sjögren syndrome & $\begin{array}{l}6727 \\
(13.4)\end{array}$ & $\begin{array}{l}7687 \\
(15.2)\end{array}$ & $\begin{array}{l}8756 \\
(17.2)\end{array}$ & $\begin{array}{l}10255 \\
(20.1)\end{array}$ & $\begin{array}{l}12018 \\
(23.5)\end{array}$ & 76.0 & $7,730,515.4$ & 643.2 \\
\hline Psoriatic arthritis & $655(1.3)$ & $783(1.5)$ & $1005(2.0)$ & $1256(2.5)$ & $1457(2.9)$ & 119.1 & $5,250,520$ & $3,603.7$ \\
\hline $\begin{array}{l}\text { Polymyalgia } \\
\text { rheumatica }\end{array}$ & $1133(2.3)$ & $1370(2.7)$ & $1582(3.1)$ & $1770(3.5)$ & $2112(4.1)$ & 83.6 & $1,731,316$ & 819.8 \\
\hline Behçet disease & $\begin{array}{c}13254 \\
(26.3)\end{array}$ & $\begin{array}{c}13754 \\
(27.2)\end{array}$ & $\begin{array}{c}14444 \\
(28.5)\end{array}$ & $\begin{array}{l}14562 \\
(28.6)\end{array}$ & $\begin{array}{l}14943 \\
(29.2)\end{array}$ & 11.1 & $11,026,314$ & 737.9 \\
\hline $\begin{array}{l}\text { Wegener } \\
\text { granulomatosis }\end{array}$ & $260(0.5)$ & $305(0.6)$ & $338(0.7)$ & $364(0.7)$ & $376(0.7)$ & 42.4 & $1,061,500$ & $2,823.1$ \\
\hline $\begin{array}{l}\text { Microscopic } \\
\text { polyangitis }\end{array}$ & $114(0.2)$ & $147(0.3)$ & $204(0.4)$ & $259(0.5)$ & $323(0.6)$ & 179.1 & $2,010,130$ & $6,223.3$ \\
\hline
\end{tabular}

than that in patients with the other symptoms (fever, 15.4 days; arthralgia, 31.0 days; skin lesion, 27.0 days).

Conclusions: Although symptoms of AOSD developed rapidly with symptoms of sore throat, fever, liver enzyme elevation and ferritin elevation, the diagnosis was frequently delayed. Our study suggests that the delayed diagnosis can be attributed in part to non-assumption of the disease. Paying attention to the combination of these symptoms can lead to an earlier diagnosis.

Disclosure of Interest: None declared

DOI: 10.1136/annrheumdis-2018-eular.3376

\section{AB1304 ASSOCIATION BETWEEN CONCOMITANT USE OF SULFASALAZINE AND DECREASE OF ANTI-CCP ANTIBODY LEVELS IN RHEUMATOID ARTHRITIS PATIENTS TREATED WITH TUMOUR NECROSIS FACTOR INHIBITOR OR ABATACEPT}

H.-H. Chen ${ }^{1,1}$, D.-Y. Chen ${ }^{2} .{ }^{1}$ Department of Medical Research; ${ }^{2}$ Department of Internal Medicine, Taichung Veterans General Hospital, Taichung, Taiwan, Province of China

Background: Anti-citrullinated protein antibodies (anti-CCP) has been found to be associated with not only the development of rheumatoid arthritis (RA), but also treatment response of RA. A recent study revealed that biologics targeting adaptive immunity, such as abatacept and rituximab, significantly decreased anti-CCP levels. $\left[{ }^{1}\right.$ However, anti-cytokine therapy, such as tumour necrosis factor inhibitor (TNFi), and methotrexate (MTX) did not significantly lower anti-CCP levels. However, whether concomitant use of sulfasalazine (SSZ) is associated with a decrease of anti-CCP levels in RA patients treated with TNFi or abatacept is unknown.

Objectives: To investigate the influence of sulfasalazine on the decrease of antiCCP IgG levels among RA patients treated with TNFi or abatacept.

Methods: After exclusion of those whose baseline anti-CCP levels (CCP0) were above the level that could be accurately measured, we enrolled biologic-naïve, anti-CCP-positive RA patients who initiated treatment with TNFi $(n=76)$, including etanercept $(n=20)$, adalimumab $(n=40)$, and golimumab $(n=16)$, or abatacept $(n=23)$. We followed anti-CCP levels (CCP1) 12 months after the initiation of biologics. A decrease of anti-CCP levels after therapy was identified if CCP1 minus CCPO was less than 0 . A multivariable logistic regression analysis was used to examine the influence of age, sex, biologic agents, disease duration, MTX, SSZ, hydroxychloroquine (HCQ), and leflunomide (LEF) on the risk of anti-CCP decrease, as shown by odds ratios (ORs) with $95 \%$ confidence intervals (Cls).

Results: Sixty-one (80.3\%) of the 76 TNFi users and 18 of the 23 abatacept users were female $(p=0.834)$. The mean $\pm S D$ age was $49.8 \pm 15.2$ years and $56.0 \pm 12.4$ years for TNFi users and abatacept users respectively $(p=0.079)$. The mean $\pm S D$ disease duration was not different between TNFi users and abatacept users $(4.7$ \pm 5.1 vs. $6.7 \pm 4.9, p=0.098)$. Thirty-eight $(50.0 \%)$ of 76 TNFi users and $7(30.4 \%)$ of 23 abatacept users concomitantly used SSZ $(p=0.099)$. Of the 74 TNFi users and 23 abatacept users, $59(77.6 \%)$ and $14(60.9 \%)$ had a decrease of anti-CCP levels $(p=0.110)$. Using multivariable logistic regression analysis to examine factors associated with a decrease of the anti-CCP level after 12 months, we found that only concomitant use of SSZ had a significant correlation $(\mathrm{OR}, 3.54 ; 95 \% \mathrm{Cl}$, 1.06-11.89; $p=0.041)$. In subgroup analysis, this positive correlation remained consistently significant in the TNFi group (OR, 5.19;95\% Cl, 1.16-23.29; $\mathrm{p}=0.031$ ), but not in the abatacept group.
Abstract AB1304 - Table 1

\begin{tabular}{lcccc}
\hline \multicolumn{3}{c}{ Univariate } & \multicolumn{3}{c}{ Multivariable } \\
\hline Concomitant DMARDs & OR(95\% Cl) & P value & OR $(95 \% \mathrm{Cl})$ & P value \\
SSZ & & & & \\
MTX & $2.95(1.11-7.86)$ & 0.031 & $3.54(1.06-11.89)$ & 0.041 \\
LEF & $2.23(0.85-5.85)$ & 0.104 & $2.13(0.58-7.77)$ & 0.254 \\
HCQ & $0.86(0.29-2.53)$ & 0.787 & $0.79(0.22-2.93)$ & 0.728 \\
& $1.55(0.55-4.41)$ & 0.409 & $0.64(0.15-2.76)$ & 0.546 \\
\hline
\end{tabular}

Conclusions: In RA patients who initiated treatment with TNFi or abatacept, concomitant use of SSZ was associated with a decrease of anti-CCP levels, especially among TNFi users.

\section{REFERENCE:}

[1] Wunderlich C, Oliviera I, Figueiredo CP, Rech J, Schett G (2017) Effects of DMARDs on citrullinated peptide autoantibody levels in RA patients-A longitudinal analysis. Semin Arthritis Rheum 46: 709-714.

\section{Acknowledgements:}

Disclosure of Interest: None declared

DOI: 10.1136/annrheumdis-2018-eular.1695

\section{AB1305 RISK OF AUTOIMMUNE RHEUMATIC DISEASES IN PATIENTS WITH PALINDROMIC RHEUMATISM: A NATIONWIDE, POPULATION-BASED, COHORT STUDY}

H.-H. Chen ${ }^{1,1,1}$, W.-C. Chao ${ }^{1}$, T.-L. Liao ${ }^{1}$, C.-H. Lin ${ }^{1}$, D.-Y. Chen ${ }^{2} .{ }^{1}$ Department of Medical Research; ${ }^{2}$ Department of Internal Medicine, Taichung Veterans General Hospital, Taichung, Taiwan, Province of China

Background: Although the association between palindromic rheumatism (PR and rheumatoid arthritis (RA) development has been widely reported, no research has estimated the magnitude of the risk of progression of PR to RA or to other autoimmue rheumatic diseases, such as systemic lupus erythematosus (SLE), systemic sclerosis (SSc), Sjogren's syndrome (SS), dermatomyositis (DM) and polymyositis (PM).

Objectives: This study aimed to examine the relative risk of development of RA, SLE, SSc, SS, DM, or PM among patients with PR compared with that in non-PR individuals using a nationwide, population-based, administrative dataset.

Methods: The study utilised 2003-2013 claims data from the Taiwanese National Health Insurance Research Database. We identified 4421 cases of PR from 2007 to 2012 and randomly chose 44210 non-PR individuals who matched (1:10) for age, sex and the year of index date without prior history of RA, SLE, SSc, SS, DM, or PM. After adjusting for age, sex, and the Charlson comorbidity index, we calculated the hazard ratios (HRs) with 95\% confidence intervals (Cls) using the Cox proportional hazard model to quantify the risk of RA, SLE, SS, DM and PM in PR patients compared with that in matched non-PR individuals.

Results: Tthe mean age \pm SD was $46 \pm 15$ years, and $70.4 \%$ of the study subjects were female. The proportion of patients with one or more $\mathrm{CCl}$ was higher in the PR group than in the non-PR group (33.0\% vs. 14.8\%, $\mathrm{p}<0.001)$. Among the 4421 patients with PR, 569 (12.87\%) developed RA, 269 (6.08\%) developed SS, 113 (2.56\%) developed SLE, $5(0.11 \%)$ developed SSc, 8 (0.18\%) developed PM, and $1(0.02 \%)$ developed DM. After adjusting for potential confounders, the patients 
with PR had an increased risk of RA (HR, 118.76; 95\% Cl, 89.81-157.04), SS (HR, 59.57; 95\% Cl, 43.87-80.88), SLE (HR, 51.56; 95\% Cl, 32.96-80.66) PM (HR, 57.38; 95\% Cl, 6.90-476.83), and SSc (HR, 13.42; 95\% Cl, 3.79-47.55) but not of DM (HR, 3.44; 95\% Cl, 0.34-34.59).

Conclusions: Patients with PR had an increased risk of developing RA, SS, SLE, PM, and SSc.

\section{REFERENCES:}

[1] Gonzalez-Lopez L, Gamez-Nava JI, Jhangri GS, Ramos-Remus C, Russell AS, Suarez-Almazor ME. Prognostic factors for the development of rheumatoid arthritis and other connective tissue diseases in patients with palindromic rheumatism. The Journal of rheumatology. 1999;26(3):540-5. PubMed PMID: 10090159

[2] Sanmarti R, Canete JD, Salvador G. Palindromic rheumatism and other relapsing arthritis. Best practice \& research Clinical rheumatology. 2004;18 (5):647-61. doi: 10.1016/j.berh.2004.05.005. PubMed PMID: 15454124.

Acknowledgements: The authors would like to thank the Biostatistics Task Force of Taichung Veterans General Hospital, Taichung, Taiwan, ROC for statistical support.

Disclosure of Interest: None declared

DOI: 10.1136/annrheumdis-2018-eular.4330

\section{AB1306 EPIDEMIOLOGY OF ACUTE ANTERIOR UVEITIS, PSORIASIS, INFLAMMATORY BOWEL DISEASE, PALINDROMIC RHEUMATISM AND SJOGREN'S SYNDROME IN TREATED ANKYLOSING SPONDYLITIS PATIENTS IN TAIWAN}

H.-H. Chen ${ }^{1}$, D.-Y. Chen ${ }^{2}$, T.-Y. Hsieh ${ }^{3}$, K.-L. Lai ${ }^{3}$, Y.-M. Chen ${ }^{1}$, C.-W. Tseng ${ }^{3}$, C.T. Lin ${ }^{3} .{ }^{1}$ Department of Medical Research; ${ }^{2}$ Department of Internal Medicine; ${ }^{3}$ Division of Allergy, Immunology and Rheumatology, Taichung Veterans General Hospital, Taichung, Taiwan, Province of China

Background: The population-based epidemiology of extra-articular manifestations of ankylosing spondylitis (AS), including acute anterior uveitis (AAU), psoriasis (PsO), inflammatory bowel disease (IBD) in Taiwan had not been investigated. Whether or not the incidences of palindromic rheumatism (PR) and Sjogren's syndrome (SS) are higher than non-AS individuals is also unknown.

Objectives: This study aimed to investigate the incidences of $A A U, P s O, I B D$, PR, and SS in a population-based AS cohort compared with a matched non-AS cohort in Taiwan.

Methods: Using 2003-2012 claims data from the Taiwanese National Health Insurance Research Database, we firstly identified 30,900 AS patients newlydiagnosed from 2006 to 2012 who received at least 3 courses of AS-related therapy (i.e., non-steroidal anti-inflammatory drugs, methotrexate, salazopyrine or corticosteroid) and defined the first date of AS diagnosis as the index date of the AS cohort. Then we randomly selected 309000 non-AS individuals matching (1:10) AS cases for age, sex and the year of the index date as the comparison cohort and defined the first ambulatory visit date of the index year as the index date of the non-AS cohort. We calculated the proportions of having AAU, PsO, IBD, PR, and SS before the index date in both cohorts. After excluding subjects with the corresponding prior diseases, we calculated the incidence rates (IRs) of $A A U, P s O, I B D, P R$ and SS for the AS and non-AS cohorts, and estimated the incidence rate ratios (IRRs) with $95 \%$ confidence intervals $(\mathrm{Cls})$ of $\mathrm{AAU}, \mathrm{PsO}$, IBD, PR, and SS for AS patients as compared to non-AS individuals.

Results: The proportion of men was $62.9 \%$, and the mean \pm SD age was $42 \pm 17$ years. Before the index date, AS patients had higher proportions of having AAU ( $8.6 \%$ vs. $0.7 \%)$, PsO (1.8\% vs. $0.5 \%)$, IBD (0.061\% vs. $0.007 \%), \mathrm{PR}(1.7 \%$ vs. $0.1 \%)$ and SS (0.33\% vs. $0.042 \%)$ compared with non-AS individuals. AS patients also had higher incidence rates of AAU (IR, 992 per $10^{5}$ years vs. 128 per $10^{5}$ years; IRR, 7.74, 95\% Cl, 7.16-8.38), PsO (IR, 167 per $10^{5}$ years vs. 73 per $10^{5}$ years; IRR, 2.30; 95\% Cl, 1.97-2.70), Crohn's disease (IR, 2.7 per $10^{5}$ years vs. 0.2 per $10^{5}$ years; IRR, $16.44 ; 95 \% \mathrm{Cl}, 2.75-98.4$ ), ulcerative colitis (IR, 6.1 per $10^{5}$ years vs. 0.1 per $10^{5}$ years; IRR, 76.03; 95\% Cl, 9.35-617.98), PR (IR, 591 per $10^{5}$ years vs. 29 per $10^{5}$ years; IRR, $\left.20.3395 ; \% \mathrm{Cl}, 17.87-23.12\right)$, and SS (IR, 84 per $10^{5}$ years vs. 6 per $10^{5}$ years; IRR, $13.61 ; 95 \% \mathrm{Cl}, 10.05-18.43$ ).

Conclusions: Consistent with prior studies, our data showed that the incidence of $\mathrm{AAU}, \mathrm{PsO}$, and IBD were higher in AS patients than non-AS individuals. We also found that AS patients had a higher incidence of PR and SS compared with non-AS individuals.

\section{REFERENCE:}

[1] Stolwijk C, Essers I, van Tubergen A, et al. The epidemiology of extraarticular manifestations in ankylosing spondylitis: a population-based matched cohort study. Ann Rheum Dis 2015;74:1373-8.
Acknowledgements: The authors would like to thank the Biostatistics Task Force of Taichung Veterans General Hospital, Taichung, Taiwan, ROC for statistical support.

Disclosure of Interest: None declared

DOI: 10.1136/annrheumdis-2018-eular.3844

\section{AB1307 DISEASE BURDEN OF AUTOIMMUNE INFLAMMATORY RHEUMATIC DISEASES IN SOUTH KOREA}

H. Kim ${ }^{1}$, S.-M. Choi ${ }^{2}$, S.-K. Cho ${ }^{1}$, S.-Y. Jung ${ }^{3}$, D. Kim² ${ }^{2}$, E.J. Jang ${ }^{4}$, Y.-K. Sung ${ }^{1}$

${ }^{1}$ Division of Rheumatology, Hanyang University Medical Center, Seoul;

${ }^{2}$ Department of Statistics, Kyungpook National University, Daegu; ${ }^{3}$ College of Pharmacy, Chung-Ang University, Seoul; ${ }^{4}$ Department of Information Statistics, Andong National University, Andong, Korea, Republic of Ireland

Background: Little is known about the epidemiology and disease burden of autoimmune inflammatory rheumatic diseases (AIRDs) in South Korea.

Objectives: To investigate the prevalence and direct medical cost of AIRDs in South Korea.

Methods: The prevalence of AIRDs including seropositive rheumatoid arthritis (RA), ankylosing spondylitis (AS), systemic lupus erythematosus (SLE), vasculitides, and other connective tissue diseases was calculated, and their trends between 2012 and 2016 were observed using nationwide claims database and the Rare Intractable Disease registration program. Direct medical costs of each AIRD in 2016 were estimated on the basis of claims charged for specific ICD-10 diagnostic codes.

Results: Among the all AIRDs, seropositive RA was most prevalent in Korea with prevalence of $188.5 / 100,000$ persons in 2016 , followed by AS $(58.7 / 100,000)$, SLE (38.0/100,000), Behçet disease (29.2/100,000), Sjögren syndrome (23.5/ $100,000)$, and systemic sclerosis $(7.1 / 100,000)$. Relatively low prevalence was observed in inflammatory myositis $(4.5 / 100,000)$, polymyalgia rheumatica (4.1/ $100,000)$, psoriatic arthritis (PsA, 2.5/100,000), and each vasculitis (0.6 3.1/ 100,000). Prevalence of most AIRDs had been increased from 2012 to 2016 while their sex and age distribution were not changed significantly. Total direct medical costs in 2016 of overall AIRDs were $\$ 263,136,087$, which were mostly composed of direct medical expenditures for seropositive RA, AS, and SLE. For the direct medical cost per person, microscopic polyangiitis $(\$ 6,223.3)$ was the highest, followed by PsA $(\$ 3,603.7)$, Wegener granulomatosis $(\$ 3,002.6)$, dermatomyositis $(\$ 2,643.1)$, and AS $(\$ 2,603.9)$.

Conclusions: Most prevalent AIRD in Korea was seropositive RA, followed by AS, Sjogren's syndrome, SLE, Behcet's disease, and systemic sclerosis. Direct medical cost per person was high in microscopic polyangiitis, PsA, Wegener granulomatosis, dermatomyositis, and AS.

Disclosure of Interest: None declared

DOI: 10.1136/annrheumdis-2018-eular.6874

\section{AB1308 FACTORS ASSOCIATED WITH THE DEVELOPMENT OF ESRD IN A RECENT LARGE SINGLE CENTRE COHORT OF PATIENTS WITH LUPUS NEPHRITIS}

I. Dasilva Santos ${ }^{1}$, H. Wilson ${ }^{1}$, T. Turner-Stokes ${ }^{1}$, T. Cairns ${ }^{1}$, L. Lightstone ${ }^{2}$.

${ }^{1}$ Department of Medicine; ${ }^{2}$ Imperial College Lupus Centre, Hammersmith Hospital, London, UK

Background: Lupus nephritis (LN) remains a major cause of morbidity in systemic lupus erythematosus. Worldwide, at 5 years about $19 \%$ (Class IV) and $4 \%$ (class V) of patients with LN develop end-stage renal disease (ESRD), depending upon the disease severity, ancestral and socio-economic factors as well as response to initial treatment. ESRD is an unusual direct cause of death in this disease but is associated with premature mortality.

Objectives: The aim of this study was to retrospectively review our large cohort of LN patients, predominantly treated with MMF and rituximab based steroid sparing regimens, who required renal biopsy for new presentation between 2010 and 2017 to analyse the factors associated with the development of ESRD.

Methods: We identified 176 patients with $L N$ from a renal biopsy database, at our tertiary Lupus Centre presenting between 01/2010 and 09/2017. The 21 patients (11\%) who progressed to ESRD were included, and using propensity score matching, were matched for age, gender and ethnicity with 63 patients who did not develop ESRD. Patients who required dialysis at presentation were excluded. Results: Baseline characteristics were similar with regard to gender, age and ethnicity between both groups. Mean follow-up was $4 \pm 17$ years overall $(2.1 \pm 1.4$ years in the ESRD group and $3.8 \pm 1.5$ years in the non-ESRD group, $p=0.0002$ ). The ESRD group had significantly higher serum creatinine at baseline (184.2 \pm 143.6 vs $89.0 \pm 48.0, p=0.031)$ and and at $12 \mathrm{~m}(256.2$ vs $79.5, p=0.001)$ and sig nificantly lower baseline eGFR (44.6 vs $68.1, \mathrm{p}=0.003$ ) and eGFR at $12 \mathrm{~m}$ (27 vs $73.1, p=0.001)$. The absence of remission at 1 year was also associated with a higher risk of ESRD ( $71.7 \%$ vs $9.5 \%, p=0.001)$, as well as the presence of positive 